\title{
Institutional Inertia and Barriers to the Adoption of Open Science
}

DOI:

10.1007/978-94-6300-178-6_6

Link to publication record in Manchester Research Explorer

\section{Citation for published version (APA):}

Gagliardi, D., Cox, D., \& Li, Y. (2015). Institutional Inertia and Barriers to the Adoption of Open Science. In E. Primeri, \& E. Reale (Eds.), The Transformation of University Institutional and Organizational Boundaries (pp. 107133). ( Higher Education Research in the 21st Century Series ). Springer Nature. https://doi.org/10.1007/978-946300-178-6_6

\section{Published in:}

The Transformation of University Institutional and Organizational Boundaries

\section{Citing this paper}

Please note that where the full-text provided on Manchester Research Explorer is the Author Accepted Manuscript or Proof version this may differ from the final Published version. If citing, it is advised that you check and use the publisher's definitive version.

\section{General rights}

Copyright and moral rights for the publications made accessible in the Research Explorer are retained by the authors and/or other copyright owners and it is a condition of accessing publications that users recognise and abide by the legal requirements associated with these rights.

\section{Takedown policy}

If you believe that this document breaches copyright please refer to the University of Manchester's Takedown Procedures [http://man.ac.uk/04Y6Bo] or contact uml.scholarlycommunications@manchester.ac.uk providing relevant details, so we can investigate your claim.

\section{OPEN ACCESS}




\title{
INSTITUTIONAL INERTIA AND BARRIERS TO THE ADOPTION OF OPEN SCIENCE
}

\begin{abstract}
The advance of networking and computing technologies offers unprecedented opportunities for the implementation of principles and practices of Open Science. Yet its uptake entails factors beyond merely technological circumstances. Substantial conditions relate to stakeholder attitudes and institutional arrangements. Based upon an esurvey and a workshop involving a wide range of important stakeholders, this chapter makes an early contribution to understanding the significant factors enabling or hindering the uptake of open science practice, in the immediate research areas involving research professionals and research organisations. We found that key drivers to the uptake of open science practices include the usefulness of publicly available research outcomes in developing personal lines of research; nonetheless, the propensity of research professionals to openly share their contributions is not high. Operational barriers such as difficulties in assessing the quality and rigour of research contributions, lack of skills and/or time to contribute to the open science movement are slowing the uptake of open science. More importantly still, there are institutional barriers linked to systemic issues such as the inadequacy of the current funding schemes. In particular, we found that institutional inertia plays a significant role in inhibiting the further opening up of the scientific process. This exploration has opened very promising insights for a roadmap for further research.
\end{abstract}

\section{Introduction}

The institutional arrangements and the organisation of undertaking scientific research that have developed since the Renaissance have changed little throughout the 20th Century. In the $21^{\text {st }}$ Century, the diffusion of Information and Communication Technologies (ICT) and new web-based tools have created a range of new possibilities for conducting knowledge creation activities by exploiting the large investments in cyber infrastructure and the networking capabilities of rich web technologies. New technologies and investments in ICTs have supported a variety of new collaborative initiatives in conducting science, these initiatives are typically described by the term Science 2.0 whereby the organisation of science is moving towards a more open process, termed appropriately Open Science ${ }^{1}$. Whilst we recognise that this is still an evolving domain, a great deal of research has been conducted on the various aspects of open science (David, 2004; Priem et al., 2010; Nielsen, 2011; Bartling and Friesike, 2014 amongst others). In trying to define this phenomenon we observe that open science is not only an uptake of Web 2.0 technologies nor only the adoption of strategic behaviours typical of the Web 2.0 revolution into scientific practices. It is also the attitudes of research performers and their organisations towards the technological infrastructure upon which these new approaches to undertaking science are based and the resultant expanding networked organisations that arise from the greater connectivity of scientists.

In this essay we define Open Science as a 'movement' that involves scientists, research organisations, funding bodies, businesses and the general public in the domain of science affecting the way scientific work is carried out and characterised by wide collaborative effort at each stage of the research process. Open science implies an overall focus on openness in science, be it to publications or research data; new methods of publication of scientific findings or processes, the growing readership of scientists' blogs and the growing number of citizen scientists taking part in scientific research projects (Peters, 2010 and Peters \& Robert, 2011; Bartling and Friesike, 2014).

The trends that are emerging from this evolutionary process point towards the increasing reliance on large databases and increased computational power, the organisation of scientific practices being increasingly bundled within collaborative teams who are operating on technological platforms and research findings that are communicated in itinere, via means which are much faster and accessible than the traditional publication channels. Indicators of this trend are many and diverse; three notable interrelating macro trends in science are: 
- a new way of doing science: data-intensive science enabled by the availability of large-scale datasets, processed through simulation software and enabled by high performance computing;

- an explosion of science/research output, including not only open science/access to scientific data but also replicability of scientific discovery, which implies access to methods, tools, data, and articles, and also new ways of conducting scientific collaborations and

- a diversification and increase in the number of actors producing scientific deliverables. These include, amongst others, citizens scientists (Burgelman et al., 2010).

The objective of this essay is to investigate the existing institutional arrangements and the adoption of new methods, highlighting conflicting interests of stakeholders that may hinder the cultural changes necessary for embracing the principles and the practices of open science. In particular, this paper explores our thoughts on addressing and analysing drivers and barriers to the adoption of open science with a focus on the roles of the research performing stakeholders in the scientific process. We focus our attention on the research performing side comprising researchers, managers, support staff and other professionals including research organisation leaders, research practitioners and communicators and the institutions within which they operate. Our aim is also to reflect on the policy implications deriving from the emergence of open science and its adoption within the existing organisational settings.

Whilst it has to be understood that this study should be considered exploratory rather than conclusive, from our analysis we can certainly infer that institutional inertia plays a significant role in inhibiting the further opening up of the scientific process. Undeniably, there are constraining factors linked to the quality of research, as fully open science features may impair appropriate evaluation or assessment of research findings but research funding methods and the absence of alternative reputation systems for scientists and scientists' performance do constitute a major barrier to open science. Research output assessment practices, adaptive research funding methods, discipline dependent practices and alternative reputation systems are certainly worth deliberation as the tools and methods of open science and its approach have proven extremely useful for conducting research at a faster pace, with results that manifest greater effect and impact.

The chapter develops along the following lines. In section 1) the idea that progressing open science as a facilitator of superior and more effective research is explored from the relevant academic literature. In section 2) we describe the methodological approach adopted in carrying out this research. In section 3) we highlight the results obtained from analysing the data collected through the e-survey and in section 4) we provide the discussion of the findings, some limitations of the current research and the conclusions highlighting promising research areas.

\section{Some reflections from the literature}

Open science is the result of a long term evolutionary process in conducting science, in recent years it has found a new and greater emphasis due to the introduction of networking information and communication technologies including pervasive Web 2.0 technologies and newer rich web technologies (known as Web 3.0 or semantic Web). This renewed emphasis can be attributed to the scientific community and policy makers identifying the megatrends described above and consequently raising questions upon the current status and potential evolutionary paths that the organisation of science might take in the future. This, albeit reductive, justification of the interests in the state of the organisation of science is easily explained by the enormous commitments that governments, public and private organisations have in terms of their remit to pursue social and economic progress, current outlays in scientific endeavours and their economic and social outcomes. In other words, the vested interests of the modern patrons of science - be they public or private - and of the scientific community, is to understand whether, and to what extent the ways of conducting science can be honed to 'bear more fruit'. This logic is now particularly cogent given the tightening of the public and private budgets for science and research.

A synthesis of the theoretical underpinning of the arguments for open science is certainly not in the remit of this paper, however in this brief review is perhaps necessary to remind the reader that pioneer work on the nature and practices of science are still the yardstick for what we now understand as science and scientific practices. 
The discussion on open science has a long standing tradition that is still shaping the current debate. Its theoretical basis can be found in the works of Merton (1942), Popper (1935, English ed., 1959) and Polanyi (1962) 2

Science does not only involve the stock of knowledge, but also the methods established to create and verify new knowledge. It involves the social and cultural values governing the production and dissemination of knowledge. Within this definition of science, Merton (1973) develops the institutional 'imperatives' that characterise modern science. Polanyi (1962) lays out 'ground rules' or professional standards involving scientists' motivations to contribute to the corpus of knowledge. Popper (1935) offers a justification of the current peer review system.

Modern investigations in the 'modes of science' do not invalidate the principles set out inter alia by Popper, Merton and Polanyi. The following contributions highlight organisational changes in the traditional process of undertaking science and novel forms of organisation of knowledge production that are emerging. Compared to traditional science, which is confined within the remit of the academe and organised in a hierarchical fashion, compartmentalised in homogeneous disciplines, Gibbons et al. (1994) and Nowotny at al. (2001) introduce and discuss the new production of knowledge as characterised by application-centred investigation, transdisciplinarity, heterogeneity and organisational diversity, social accountability and reflexivity (Mode 2 of knowledge production). More recently, Carayannis and Campbell (2006) and Wagner (2008) describing perhaps a Mode 3 of knowledge production, highlight how scientific endeavours are increasingly characterised by multilevel and networked clusters of knowledge production.

Core to the scientific process, from the more traditional form of organisation to the modern networked science is the dyad 'creation' and 'dissemination' of knowledge; the first driven by curiosity, ingenuity and ethics, the second validated by sceptical peers and diffused by the available means of communication.

The process is undertaken under the aegis of a patron. Eamon (1985) and David (2004 and 2005) argue that public knowledge or open science derives from the Scientific Revolution where, departing from the dominant regime of secrecy in the pursuit of Nature's secrets, scientists recognised the invaluable contribution to science that a collaborative approach might allow. Notwithstanding the complementarities and idiosyncrasies that confidentiality and openness present in relation to the dissemination of science, the principle of priority of attribution constitutes a strong incentive to disclosure and as a consequence, accumulation of knowledge increases at a faster rate and more organically than if it were undertaken in secrecy ${ }^{3}$ (David, 2004).

Given the support of the State to the promotion of science, opening the scientific process became an aspirational target which experienced different fortune throughout the years. Recently, however, it has found renewed vigour especially since successful examples of some open science initiatives ensuing on the diffusion of networking technologies.

Fecher and Friesike (2014) present a concise synthesis of the current debate on open science; they identify five streams, or schools of thought, informing the contemporary discourse. The authors term these 1) 'public school' concerned with the public engagement and understanding of knowledge; 2) the 'democratic school' which is mainly concerned with public access to knowledge; 3) the 'pragmatic school' which stresses the importance of collaborative research for an efficient use of resources; 4) the 'measurement school' which is concerned with the assessment of the 'quality` of the research output and looks at alternative metrics for the evaluation of scientific contributions and personal contribution to sciences; and finally 5) the 'infrastructure school' which is mostly concerned with the technological aspects of open science and the role of new information and communication technologies in fostering open science.

As Fecher and Friesike (2014) point out, the discourse on open science is rather complex as it develops along many intertwined domains, entailing many different stakeholders interacting at different levels. We can argue that science is a systemic occurrence and that it directly involves a variety of stakeholders with interests and stakes in the process which are rarely aligned. The attention of scientists and research professionals, research organisations, research funders and policy makers has long been focussed on the various expressions of open science notably, open access to publications, e-infrastructures, data repositories and other practices. A synthesis and relevant references of the key features of open science is presented in the table below: 
Table 1: Key features of open science practices

\begin{tabular}{l} 
Open Science practices \\
\hline Open access to \\
publications/open access \\
publishing
\end{tabular}

Open access to data

\section{Negative results publications}

Open lab notebooks

Research social networks

Alternative reputation
systems

Key features

Publications that use a funding model that does not charge readers or their institutions for access.

Such publications may be further redistributed and reused for research, education and other purposes.

A procedure '...whereby the experts consulted on an article's worthiness submit their comments for publication along with the article, thus stimulating discussion in a way the article alone could not.' (p.3)

A key tool to bring together people and ideas in a way that catalyzes science and innovation.

It helps to maximize the research potential of new digital technologies and networks and provides greater returns from the public investment in research.

Enabling later researchers to learn from earlier researchers' failures, so that resources (including time and money) would not be spent on repeating the same failures.

(Virtual) lab notebooks containing information about all the components and processes related to a research project. Scientists report what they actually do. An open lab notebook includes all the information that any scientist needs to be able to understand and replicate the research.

Digital networks '...where scientists freely and easily share published work, experimental data, ideas and opinions and mutually benefit from the open and collaborative realm that is emerging in the digital age' (p.342).

Beyond traditional metrics based on citation analysis, '...scholarly impact would cover usage, captures, mentions and social media... Metrics should include mentions in blogs and other nontraditional formats, open review forums, electronic book downloads, library circulation counts, bookmarks, tweets and more. Such alternative metrics provide a more complete view of peer response to scholarly writings and better demonstrate the relative position of a research grant applicant and potential for influential work. (p.35)

\section{Literature/source}

Directory of Open Access Journals (DOAJ) ${ }^{4}$

Dallmeier-Tiessen et al. (2010)

Björk and Solomon

Okerson and O'Donnell (1995)

European Commission (2012)

OECD (2007)

Goetz (2007)

Kundoor and Mueen (2010)

Sanderson (2008)

Rinaldi (2014)

Buschman and Michalek (2013) 


\begin{tabular}{lll}
\hline Open Science practices & Key features & Literature/source \\
\hline Big data analysis & $\begin{array}{l}\text { Analysis of extremely large pools of structured or } \\
\text { unstructured data that could not be processed using } \\
\text { traditional analysis methods. } \\
\text { A culture of data sharing and open access to big data sets } \\
\text { can significantly accelerate the process of scientific } \\
\text { research and breakthrough. }\end{array}$ & Choudhury et al. (2014) \\
& $\begin{array}{l}\text { Blogs published by scientists with a main focus on } \\
\text { disseminating or commenting upon science. Through } \\
\text { this way scientists share their research interests, } \\
\text { thoughts, work in progress and research outcomes. }\end{array}$ & Wilkins (2008) \\
Science blogs & $\begin{array}{l}\text { Science based on crowd sourcing which facilitates } \\
\text { research in a more effective (including cost-effective) } \\
\text { and collaborative manner. }\end{array}$ & Franzoni and Sauermann, \\
Crowd-source science & H. (2014) \\
\hline
\end{tabular}

The first steps towards opening up the outcomes of the scientific process have entailed the dissemination of publications through open access to publications and diffusion of the data from which such research originates. Open access to publication, as we shall see below, has been at the centre of a lively debate since the mid-1990s whilst the first inroads in open data were made at the beginning of the current century.

To have a perspective on the scale of the current open access publishing industry, the Directory of Open Access Journals (DOAJ), one of the most important associations of open access publishers by number of publications, consists of some 10,000 journals in all disciplines. To date the number of articles published by journals listed in the DOAJ is about 1.7 million. Adding to these, traditional subscription-based journals have, since the early 2000s, opened up to the possibility of publishing in open access mode and many traditional publishing houses are developing their open access catalogues of journals.

The argument at the basis of the open access to publications debate originates from the observation that the public is actually paying twice for the production of knowledge, once in the form of public research funding and a second time to access the knowledge that has been produced. The possibilities offered by electronic networks can provide a way out of this impasse and extend the reach and accessibility of scientific publications. Opening up the peer review process would also guarantee the scientific rigour of ePublications (Harnad 1994). This system could make the publishing industry in the field of scholarly publications practically redundant ${ }^{5}$. Okerson and O'Donnell, J. J. (1995) argued that whilst these new ideas are enticing, their slow uptake is due to the fact that the academic community is basically satisfied with the status quo of the scientific publishing process. In other words, academics are comfortable in operating within the limitations of the traditional process, even if it might defer or stop altogether the publication of their own research. The incentive system in place is such that the alternative publishing of ePublications, not at all favoured by promotion and tenure committees, altogether discourage this form of publication. The reaction to the perceived bias associated with the evaluation of research through metrics such as journal standings (measured by the journal impact factor) and research standing (measured by the number of citations) has spurred the debate on alternative reputation systems - at the time of writing one such example is Altmetric (altmetric.com). Buschman and Michalek (2013) explore the drawback of traditional evaluation metrics and propose a taxonomy based on 1) Usage of the article (downloads, views etc); 2) Capture (bookmarks, favourites readers etc.); 3) mentions (in blog posts in the news in comments and reviews; 4) social media (tweets, likes, ratings and shares); and 5) Citations (citation counts in indexing sites). These metrics, the authors argue, reflect more accurately the impact of research in an era of increased competition for research funding and tenure.

The importance of open access to scientific publications particularly around issues of dissemination and research impact has not gone unnoticed. The earlier work of Antelman (2004), McVeigh (2004), and Harnad \& Brody (2004), investigated the research impact of open access publications. Antelman (2004) found that in a sample of some 2,000 
articles in four disciplines with different rates of open access adoption - mathematics, electrical and electronic engineering, political science, and philosophy - open access publications had a greater research impact than traditional articles in terms of citations. McVeigh (2004), in a study for the publisher Thompson, assessed the impact factor and citation patterns of open access journals included in the ISI Citation Database. The study found that the open access journals were poorly represented in the ISI Databases and their impact factor was relatively low compared with that of traditional subscription journals, even though a handful of open access journals were classed in the top 10\% in their category. Open access journals fared rather better in terms of Immediacy Index, suggesting that open access publications were accessed and cited more rapidly than papers in traditional subscription journals. Harnad and Brody (2004) argued that a more appropriate comparison between research impact of open access and traditionally published papers should focus on different citation patterns of open access papers and non-open access papers published in the same journal. The authors found that open access papers were cited between 2.5 and 5.8 times more than non-non open access papers published in the same journals.

Studies on the diffusion of open access journals and publications, publishing models and attributes (DallmeierTiessen et al, 2010), their comparative impact on research and the links between open access and citation counts (Björk and Solomon, 2012; Solomon et al. 2013 to name but a few) have been intensively studied in the last ten years. Gaulé and Maystre (2011) examined a dataset of over 4,000 papers published between 2004 and 2006 in one of the world's top scientific journals, the Proceedings of the National Academy of Sciences (PNAS) and found that the correlation between open access and citation is only marginal and not statistically significant when the quality of the paper and the status of the author within the research area are taken into account.

Access to data has recently been at the centre of attention. Data sharing is extremely important in science as replicability of studies, validation of results and extension of research can be enabled only through the re-use of data upon which original publications are based (Gorgolewki et al. 2013). It is also undeniable that open data is the first step towards data aggregation and big data analysis, a promising research strategy opening up possibilities of largescale studies and sample-bias corrections (Choudhury et al. 2014). Data sharing also acts as a deterrent to fraud, encouraging the publication of high-quality research. In other words, data sharing plays a dual role in advancing knowledge creation and establishing best practices against fraudulent behaviours, however, raw data is of little or no value for researchers other than those who have collected them. This hardly justifies any form of protection. Nonetheless, when time and effort to systematise and appropriately document the information with the relevant metadata, their value becomes intrinsically high and adds to the burden of researchers who would likely prefer to be engaged in research rather than learn and practice data curation (Nature, 2011 and Grand et al. 2014). Yet, when research data has been collected through public funded research grants, it is expected that it will be made openly available.

This concept, whilst pioneered by not-for profit research foundations such as the Wellcome Trust (2003) and the National Institute of Health in the US for grants over $\$ 500,000$ in 2003, has progressively pervaded the policies of almost all public research funders in the US. In the UK the Research Councils have policy regarding data-sharing for supported research and in the EU, the European Commission requires that funding bids are complete with a data management plan and the data have to comply with the standard adopted by the Commission Services. Within these frameworks it is not uncommon that a period of exclusive use of the research data is granted to the researcher(s) who have collected them for a limited period of time.

The OECD (2007) has issued principles and guidelines for the access to research data obtained through publicly funded initiatives. The guidelines specify that research data should be made available to the research community in a timely, user-friendly format, preferably from the Internet and at the lowest possible cost. Moreover, the guidelines suggest that authors of scientific publications should make the data used in their work available. This 'suggestion' has been adopted by several journals (Pampel and Dallmeier-Tiessen, 2014) including those published by the highprofile publisher Nature, which requires that materials, data and protocols used in experiments should be made promptly available to the reader upon request, preferably in a downloadable file from an institutional repository (OECD, 2007; Whyte and Pryor, 2011).

In theory, systems for the public access to research data collected in the course of publicly funded research are in place in most of the research active, Western countries; in practice, there are still many issues to be resolved. The costs of opening up research data comprise 1) Infrastructure and Administration, 2) Standardisation, 3) Human Resources and 4) Opportunity costs. These costs are not supported by grant agreements indefinitely and after the grant comes to an end, these are left with the researchers and their organisations (Wilhelm et al. 2014). Even when a 
public data infrastructure is available, it is still unclear how it should be funded. Berman and Cerf (2013) raised a sensible point when looking at the 'quantity' of data collected by federally funded R\&D projects and noted that the variety of initiatives for data infrastructure sponsored by the US Government and the various agencies stated that

federal $R \& D$ agencies are unlikely to allocate enough resources to support all federally funded research data.

The costs of infrastructure would absorb too great a proportion of a budget that must support both innovation and the infrastructure needed to drive innovation. (P. 616).

There is one more aspect of research data sharing that needs consideration. Undeniably, research organisations might have institutional repositories and the costs for infrastructure, managing and maintaining them might be factored into budgets on a rolling basis from government funds or grants however, following the logic proposed by Berman and Cerf (2013), at one point the costs might become unsustainable. The involvement of the researchers in coding, documenting and curating the data that have been collected becomes strictly necessary prior to the integration in the repository. Yet, a reward system for research data work is non-existent. Two recent studies highlight very clearly the problem of sharing research data from the researchers' perspective. Haeussler et al. (2014) using a survey of over 1,000 bio-scientists based in Germany and in the UK found that researchers were more likely to share information if the gain derived from expected reciprocity outweighs the loss of competitive edge derived from sharing. Certainly, in research areas where competition is more fearsome, the incentive to share any information would be extremely low. Career stage also has an impact, an untenured researcher has very little incentive to share compared to a senior researcher. Andreoli-Versbach and Mueller-Langer (2014) analysed the data-sharing behaviour of some 500 empirical economists and management scholars, finding that their attitude to sharing data is often 'professed but seldom practised'. Interestingly they found that the likelihood that the researcher shares data increases predictably with 1) tenure, but also with 2) the standing of the researchers, 3) if data sharing is mandatory for the publications and, lastly, 4) if the scientists have a personal preference for open science.

A publication bias towards positive results has been evidenced since the 1960s. Smart (1964) highlighted that in psychological research there is a selection bias against the publication of negative results as only $9 \%$ of the papers in this discipline were reporting upon them. The reasons for this bias are attributable to the author selection - authors are less likely to decide to publish negative research results - and to greater editorial scrutiny. Fanelli (2012) highlights that, due to competition for research funding and citations, negative result publications are disappearing from most disciplines, even though they are particularly useful for the progress of science (Goetz, 2007; Hayes and Hunter, 2012; Foster and Putos, 2014). Several initiatives have been implemented in order to counteract this publication bias. These range from positive approach journals to negative results publications ${ }^{6}$ (Wilcox, 2014) to the creation of journals where only negative experimental results are sought for publication (Kundoor and Mueen; 2010).

Information Technologies (IT) feature strongly in open science practice as an enabler. Practices such as open access to publication and open data rely strongly on the infrastructural capacity of IT. Other practices, using the IT infrastructure, are mostly a consequence of the behaviour of scientists towards said technologies. Amongst these practices are research social networks, open lab notebooks, science blogs and crowd sourcing.

Research social networks, from platforms such as ResearchGate to Twitter, are not intensively used as platforms to share published ongoing work, ideas, opinions or experimental data, all activities that may foster open collaboration and build a dialogue with the general public; instead they are increasingly becoming a means for public visibility of scientists, especially for the benefit of research funders, and a platform where constructive scientific debate takes place (Rinaldi, 2014). At one end of the spectrum activities addressed to the scientific community such as open lab notebook practices are employed by scientists to disseminate their findings as they are achieved. This practice is mainly used to claim priority on specific research endeavours and to stimulate the dialogue about the research undertaken. It has an interesting secondary effect of forcing a higher standard of recordkeeping given that it is open to other scientists to peruse. The risks, however, are that data and/or methodologies can be employed by competing researchers, if, further down the line, the research outcome becomes of commercial value, it will not be patentable (due to non-originality) and, for the same reason, some journals will not publish results that have previously appeared in the public domain (Sanderson, 2008). On the other end of the spectrum, science blogs are a popular way to engage in science communication in a timely way and to relate to the public who otherwise would not have the skills to engage with traditional scientific publications (Wilkins, 2008). Crowd source science entails the participation of citizens and/or professional scientists to an open research endeavour. Many crowd science experiments have become very successful over the last decade including Galaxy Zoo, Fold it and Polymath. Nielsen (2011) and Franzoni and Sauermann (2014) highlight the point that crowd science projects are 
directed to professional scientists to exploit economies of scale in the scientific production and to citizen scientists in order to extend research capabilities in the collection of data or in non-technical labour intensive activities. These authors have highlighted that such ventures are heterogeneous and present many organisational challenges; thus, they also identify crowd science, as a new means of organising science that allows for 'significant experimentation' and considerable scope in the types of problems that can be addressed (Franzoni and Sauermann, 2014, p7).

In this chapter we focus our attention on the research professionals and the organisations within which they operate. Universities and research institute researchers in both the public and private sectors have a significant strategic role to play in the process of open science. The potential benefits of open science offered to researchers derive from the openness of the process and the opportunity to draw on a much wider and deeper range of expertise, including interdisciplinary expertise, than would otherwise be possible. Moreover, the public engagement of open science is likely to have wider impact and outreach as the research endeavour is open to scrutiny by the scientific community as well as by the public. This facilitates the research strategies of individual researchers, establishes an open system that mitigates misconduct and is an efficient use of resources across the science base.

\section{Methodology: definitions and survey}

The methodology used in carrying out the analysis presented below consists of an e-survey conducted by the project partners led by Inno AG and a stakeholder workshop held at the European Commission, in Brussels, on the 4th of November, 2013. The survey and the workshop were part of the deliverables for a briefing prepared for the European Commission entitled The Prospects of Science 2.0: policy implications.

The survey was launched in October 2013 and was live and monitored for 4 weeks. The respondents were recruited through the professional networks of the research team. It attracted the interest of over 200 respondents. One hundred and eleven questionnaires returned were adequately completed and selected for analysis. Respondents were from 16 Countries, largely from Europe $(n=89)$ and North America $(n=11)$. Their occupations are Researchers $(n=69)$, Research Project Managers $(n=6)$, Research Support Staff $(n=26)$ and Others $(n=8)$, consisting of Research Communicators i.e. Journalists using research publications and findings in their work, University leaders and Research Practitioners.

The age of respondents has been classed according to three main classes: over $50(n=22)$; between 34 and 49 $(\mathrm{n}=48)$ and younger than $33(\mathrm{n}=37)$. The majority of the respondents are employed by a University $(\mathrm{n}=57)$; by a public research organisation or a public body $(n=27)$; by a private research organisation $(n=7)$; by a company (over 250 employees, $n=5$; SME, $n=7$ ) or were free lancers $(n=7)$.

The distribution of respondents by field of science, according to the Field Of Science (2007) is as follows: Natural Sciences $(n=34)$; Engineering and technology $(n=29)$; Medical and Health Sciences $(n=7)$; Agricultural Sciences $(n=4)$; Social Sciences $(n=27)$ and Other $(n=10)$.

The questionnaire comprised 6 main blocks of questions. The first block of questions explores the respondents' perceptions of open science. The second and third blocks investigate the use of Open Science practices and their perceived impact on conducting and disseminating research results. The fourth and fifth blocks of questions are intended for assessing the usefulness of publicly shared scientific outcomes and the propensity/willingness of the participants to openly share their research outcomes. The last group of questions focuses on the barriers to open science. All blocks of questions have an 'other, please specify' option where the respondents could enter open text to elucidate their answer. This option has been used by the majority of the respondents.

The questions encompassing ranked responses have been assessed for consistency using Cronbach's-alpha.

The results of the survey were presented and discussed at the workshop. At the workshop other contextual issues were raised and highlights from the debate on the relationships between research performers and the organisations in which they work will be integrated in the discussion of the findings. 


\section{Findings}

The descriptive statistics from the survey reveal that the respondents have a good understanding of Open Science and what this concept entails, although their expectations towards its revolutionary potential are rather cautious. In the next table, we summarise the responses.

Table 2: Perception of open science (general)

\begin{tabular}{llll}
\hline OS statements & Mean score & $\begin{array}{l}\text { Standard } \\
\text { deviation }\end{array}$ & N \\
\hline New modus operandi for science & 1.77 & 0.735 & 111 \\
Support better science and improve the quality & 1.67 & 0.730 & 111 \\
Reproducible science and uncover mistake & 1.68 & 0.700 & 111 \\
Current practices don't fit the needs & 1.60 & 0.651 & 111 \\
Lead to less inequality for researchers & 2.14 & 0.830 & 111 \\
\hline Notes: 4 points Likert's scale (1 = disagree, 4=totally agree); Reliability: Cronbach's alpha $=0.79$
\end{tabular}

The only mean score above the median (2) relates to the statement that open science has the potential to level the playing field amongst researchers, especially in those areas of research where resources to produce new data or access a wider pool of knowledge are determinants in successfully completing research projects, namely, the Natural Sciences, Engineering and Technology and the Social Sciences to a lesser degree. Open science as a 'leveller' of opportunities in conducting science is seen positively by Public Research Organisations compared to Universities and by SMEs compared to Large Enterprises.

Two further questions were included in order to establish whether, in the pursuit of the open science disclosing process early results are seen favourably by those involved in research. Two statements were presented:

Table 3: Initial results and $H Q$ peer-review

\begin{tabular}{llll}
\hline OS statements - disclosure and peer-review & $\begin{array}{l}\text { Mean } \\
\text { Score }\end{array}$ & $\begin{array}{l}\text { Standard } \\
\text { Deviation }\end{array}$ & N \\
\hline $\begin{array}{l}\text { Keeping some process and initial results private } \\
\text { is necessary }\end{array}$ & 2 & 0.751 & 111 \\
$\begin{array}{l}\text { Scientific publications should be restricted to } \\
\text { high quality and peer reviewed work }\end{array}$ & 2.25 & 0.919 & 111 \\
\hline Notes: 4 points Likert's scale (1= disagree, 4=totally agree) & & & \\
\hline
\end{tabular}

The respondents were somewhat neutral in respect of the need to keep the research process and initial results concealed $($ mean score $=$ median). However, older research professionals were proportionately more in favour of keeping some process and initial results private than their younger counterparts (Spearman's correlation of 0.27 with $\mathrm{p}$ value $<0.05)$. Greater emphasis was given to the importance of peer-review as the only acceptable means to ascertain scientific rigour.

The following two blocks of questions investigate the use and impact of open science practices. The items considered are those practices commonly associated with open science and the respondents were invited to rate their use on a $1-5$ Likert Scale where $1=$ 'never heard of it' and $5=$ 'regular use' and the potential impact the items have on science according to the scores $1=$ 'no impact' to $5=$ 'very high'. Chi-square test for each item scored for 'Use' and 'impact' shows evidence of a significant relationship (at the $\mathrm{P}<0.01$ level).

Table 4: Use and Impact of open science practices

\begin{tabular}{llllll}
\hline Open science practice & $\begin{array}{l}\text { Use } \\
\text { Mean } \\
\text { Score }\end{array}$ & $\begin{array}{l}\text { Impact } \\
\text { mean } \\
\text { score }\end{array}$ & $\begin{array}{l}\text { Use } \\
\text { Standard } \\
\text { deviation }\end{array}$ & $\begin{array}{l}\text { Impact } \\
\text { Standard } \\
\text { deviation }\end{array}$ & $\mathbf{N}$ \\
& 4.43 & 4.26 & 0.901 & 1.142 & 111 \\
\hline Open access publications & 2.95 & 3.09 & 1.052 & 1.671 & 111 \\
Negative results publications & & & &
\end{tabular}




\begin{tabular}{llllll}
\hline Open science practice & $\begin{array}{l}\text { Use } \\
\text { Mean } \\
\text { Score }\end{array}$ & $\begin{array}{l}\text { Impact } \\
\text { mean } \\
\text { score }\end{array}$ & $\begin{array}{l}\text { Use } \\
\text { Standard } \\
\text { deviation }\end{array}$ & $\begin{array}{l}\text { Impact } \\
\text { Standard } \\
\text { deviation }\end{array}$ & N \\
\hline Open data and linked open data & 3.78 & 3.99 & 1.074 & 1.505 & 111 \\
Open lab notebooks & 2.75 & 2.51 & 1.202 & 1.747 & 111 \\
Research social networks & 3.87 & 3.07 & 1.010 & 1.469 & 111 \\
Open reviews & 3.19 & 2.91 & 1.195 & 1.703 & 111 \\
Alternative reputation systems & 2.81 & 2.57 & 1.411 & 1.910 & 111 \\
Big data analysis & 3.33 & 3.48 & 1.170 & 1.762 & 111 \\
Science blogs & 4.06 & 3.07 & 1.064 & 1.367 & 111 \\
Crowd-source science & 3.24 & 2.85 & 1.162 & 1.764 & 111 \\
\hline
\end{tabular}

Notes: 5 points Likert's scale; Cronbach's alpha: Use $=0.852$; Impact $=0.884$

The respondents declared that the main open science practices used in the course of their research activities related to Open Access to Publication, Science Blogs, Research Social Networks and Open Data/Linked Open Data whilst the main impact on their research is given by Open Access to publication and Open/Linked data.

Importantly, the mean scores for use and impact of 6 out of 10 items do not differ significantly accordingly to the $\mathrm{t}$-stats test ( $\mathrm{p}$ value > 0.5) indicating that their use somehow matches the impact these practices have on their research activities. Significant in this respect is the high mean score of Open Access publications and Open/Linked Data for both 'use' and 'impact' indicating that the respondents consider these two Open Science practices very highly in the advance of their research.

Conversely, the mean scores for use and impact of Research Social Networks, Open Reviews, Science Blogs and Crowd Sourcing are significantly different. Indicating that these open science practices are used more than their impacts justify their use. In other words, the hypothesis that we are here exploring is that an open science practice is used if its impact on own research justifies the effort of using it, i.e. if the mean scores of use and impact are not significantly different.

Table 5: Use/impact differences paired t test

\begin{tabular}{llll}
\hline Mean difference & (use-impact) & T-test & $\mathbf{N}$ \\
\hline Research social networks & 0.802 & $6.884^{* * *}$ & 111 \\
Open reviews & 0.279 & $2.118^{* *}$ & 111 \\
Science blogs & 0.991 & $7.924^{* * *}$ & 111 \\
Crowd-source science & 0.396 & $2.976^{* *}$ & 111 \\
\hline
\end{tabular}

Sig. $* *$ Pvalue $<0.05 ; * * *=$ Pvalue $<0.01$

These results indicate that Research Social Networks, Open Reviews, Science Blogs and Crowd Science are used for reasons other than the impacts these practices might have on own research activities. These results are rather general as there is no significant difference depending on whether the respondent is active in a particular field of research, a type of organisation or her/his age.

The next block of questions is directed at assessing the usefulness of open science outcomes to progressing research activities and the propensity of research professionals to opening up, in the spirit of open science, the outcomes of their research to the public. The 'Usefulness' of shared outcomes has been assessed on a 4 point scale where 0 is 'not useful' and 4 is 'very useful'. The variable 'Willingness to share' assumes the value 1 if the respondent is willing to share the outcome of his research and 0 is she/he is not. In the case the item is 'not applicable' a 'missing value' is registered.

Table 6: Open access to research outcomes - Usefulness and Propensity to Share

\begin{tabular}{llllllll}
\hline Research outcomes & $\begin{array}{l}\text { Usefulness } \\
\text { Mean } \\
\text { Score }\end{array}$ & $\begin{array}{l}\text { Usefulness } \\
\text { Standard } \\
\text { deviation }\end{array}$ & $\begin{array}{l}\text { Share } \\
\text { Yes }\end{array}$ & $\mathbf{U} * \mathbf{S})$ & $\begin{array}{l}\text { U*S } \\
\text { Standard } \\
\text { deviation }\end{array}$ & $\begin{array}{l}\text { Adjusted } \\
\text { Usefulness } \\
\text { mean } \\
\text { score }\end{array}$ & $\mathbf{N}$ \\
\hline
\end{tabular}




\begin{tabular}{llllllll}
\hline Bibliographies & 2.05 & 0.888 & 0.98 & 2.00 & 0.924 & 2.02 & 104 \\
Publications & 2.75 & 0.579 & 0.98 & 2.72 & 0.643 & 2.75 & 105 \\
Draft and incomplete papers & 1.74 & 0.783 & 0.50 & 0.99 & 1.153 & 1.74 & 101 \\
Negative Results & 2.07 & 0.922 & 0.91 & 2.05 & 0.999 & 2.18 & 94 \\
Datasets & 2.53 & 0.772 & 0.86 & 2.29 & 1.112 & 2.60 & 98 \\
Source code & 2.16 & 1.005 & 0.86 & 2.23 & 1.113 & 2.45 & 80 \\
Workflow (experiment log) & 1.72 & 1.002 & 0.86 & 1.75 & 1.131 & 2.01 & 80 \\
Figures, presentations and & 2.21 & 0.799 & 0.95 & 2.15 & 0.896 & 2.22 & 105 \\
supporting material & & & & & & & \\
Annotation and comments & 1.98 & 0.963 & 0.79 & 2.00 & 1.202 & 2.00 & 103 \\
\hline
\end{tabular}

Notes: Usefulness: 4 points Likert's scale; Cronbach's alpha: 'Useful' = 0.849; 'Willingness to Share': three variables: 'Not Applicable' (Missing Value), 'Yes' $=1$, and 'No' $=0$. The variable defined as $U^{* S}$ is the product of 'Usefulness' times 'Willingness to Share'. The variable takes the value 0 , whatever the rate of usefulness, if the respondent is not willing to share and the value of attributed to 'Usefulness' if the respondent is willing to share. A Missing Value is reported in case the outcome is 'Not Applicable'. Cronbach's alpha of $U^{*} S=0.790$.

The descriptives above show that items such as Publications, Datasets, Source Code, Negative results and Bibliographies are considered useful by the respondents; their willingness to share is also very high ranging from 50\% of the respondents willing to share Drafts and Incomplete papers to $98 \%$ of the respondents who would willingly share their Publications and Bibliographies.

Direct comparison between the two variables is not possible as 'Usefulness' of research outcomes is assessed through a 4 point scale whilst the propensity to make available the outcome to the general public is a dichotomous variable. To overcome this impasse we have calculated a further variable $\left(\mathrm{U}^{*} \mathrm{~S}\right)$ which also takes into account those respondents who declared that the particular outcome was not relevant in their research activities.

Table 7: Usefulness and sharing openly research outcomes: a comparison

\begin{tabular}{llll}
\hline Research outcomes & $\mathbf{U}-(\mathbf{U} * \mathbf{S})$ & T-Test & N \\
\hline Draft and incomplete papers & 0.752 & $8.412^{* * *}$ & 101 \\
Negative Results & 0.128 & $2.413^{* *}$ & 94 \\
Datasets & 0.316 & $3.708^{* * * *}$ & 98 \\
Source code & 0.225 & $2.983^{* * *}$ & 80 \\
Workflow (experiment log) & 0.262 & $3.606^{* * *}$ & 80 \\
Annotation and comments & 0.291 & $4.091 * * *$ & 103 \\
\hline Sig. $* * P$ value $<0.05 * * * *=P$ value $<0.01$ & & &
\end{tabular}

In this block of questions, the hypothesis we are testing here is whether there is a willingness to share a research outcome corresponding to its usefulness in conducting research activities or if the respondents find it useful for their own research process to consult or use material produced by other scientists but are less willing to share the intermediate outcomes of their research. Comparative analysis shows that Publications, Bibliographies and Figures, Presentation and other support material, are both useful in conducting research activities and are shared willingly by the respondents. This is unsurprising as those outcomes are increasingly part of the typical publication and dissemination process. These results only show the support of the respondents to open access to publications and dissemination.

T-tests evidence that drafts and incomplete papers, datasets and the other items highlighted in Table 7 are shared less willingly with other research professionals than they are considered useful for their own research.

Is the propensity to share different according to the various areas of research, the type of organisation the respondent works at or the age of the respondents?

'Useful therefore share' behaviours are particularly high in the Natural Sciences, Engineering and Technology and Social Sciences but only Publications, Datasets, Source code and Annotations and comments are statistically significant. There is no statistically significant difference in propensity to share between different types of organisations. The age of the respondent is slightly linked to the propensity to share research outcomes. In particular, respondents in the two age groups younger than 50 Years of Age share systematically and are more likely to share 
than respondents older than 50. In particular the relationship between age and willingness to share is particularly strong and statistically significant for Bibliographies, Draft and incomplete publications, Source code and Annotations and Comments.

In the scoping study we have identified 4 operational barriers to open science; these concern 1) the difficulty of assessing the quality and the impact of research results when they are disseminated in their draft forms or through means other than peer-reviewed publications; 2) the time consumed by research professionals in contributing to open science initiatives and 3) the difficulty encountered in engaging the public in scientific projects in terms of time/resources needed and technological platforms involved and finally 4) research professionals may lack the skills to set up, deploy and maintain open science tools necessary to contribute to open science platforms, data repositories and dissemination fora.

The responses are collected through a binomial variable where 'yes' $=1$ and 'no' $=0$.

Table 8: Operational and Institutional barriers

\begin{tabular}{llll}
\hline \multicolumn{1}{c}{ Operational Barriers } & Mean & $\begin{array}{l}\text { Standard } \\
\text { deviation }\end{array}$ & N \\
\hline $\begin{array}{l}\text { Assessing quality and impact of the research results } \\
\text { Time consumed in participation in open Science }\end{array}$ & 0.51 & 0.502 & 111 \\
Public interest/involvement & 0.30 & 0.459 & 111 \\
Skills of the researchers in using the tools & 0.15 & 0.362 & 111 \\
\hline \multicolumn{1}{c}{ Institutional Barriers } & 0.34 & 0.477 & 111 \\
\hline & Mean & Standard & $\mathbf{N}$ \\
Funding & 48.6 & 0.502 & 111 \\
Inertia of the science system & 60.1 & 0.491 & 111 \\
\hline
\end{tabular}

Assessing both quality and impact of the research results is the main operational barrier in the uptake of open science which was selected by $51 \%$ of the respondents whilst $34 \%$ of the respondents declared that the skills of researchers to using open science tools are a barrier. Thirty per cent of the respondents that they lack time to participate in open science practices.

Institutional barriers have been identified as 1) lack of funding to undertake open science initiatives and 2) inertia in the science system, which is still linked to the traditional organisation of science practices and hinders the uptake of open science by not providing incentives to research professionals to share publicly their research work.

Approximately half of the respondents agree that funding for open science is inadequate and that current funding practices, where only some of the open science practices can be written into proposals, might not be conducive to open science.

A very high and significant $60 \%$ of the respondents stated that the main institutional barrier to the uptake of open science is concerned with the inertia of the science system still steeped in Science 1.0 practices and not rewarding alternative modes of conducting or disseminating research.

The inertia of the science system element is particularly important and has been investigated further by looking at the attitudes towards open science of the research community in which the research professionals operate. In particular, the work environment of the respondents is at best neutral in respect of the involvement of research professionals in open science (in $37 \%$ of the cases) whereas in almost $20 \%$ of the cases, respondents stated that their peers or superiors would not appreciate their engagement in open science initiatives.

We have also investigated how barriers relate to the characteristics of the respondents (Field of Science, Type of Organisation, Country and Age of the respondent). Chi Square tests were carried out for this purpose. Fields of Science, Type of Organisations and Country of the respondent did not evidence any particular link with barriers however, Chi Square tests between Age and Barriers flagged a few significant connections. For the reason that age of the respondent might be taken as a proxy for career advancement, further investigation was conducted in order to 
ascertain the nature of this possible connection. Spearman's Rho correlations were calculated between the various barriers and the age of the respondent.

Table 9: Correlations between Operational Barriers and Age of Respondents

\begin{tabular}{lll}
\hline \multicolumn{1}{c}{ Operational Barriers vs Age of Respondent } & $\begin{array}{l}\text { Spearman's } \\
\text { rho }\end{array}$ & N \\
& & \\
\hline Assessing the quality and the impact of the research results & $0.290^{* * *}$ & 107 \\
Time consumed in participation in Open Science & $0.217^{* *}$ & 107 \\
Public interest/involvement & 0.016 & 107 \\
Skills of the researchers in using the tools & $0.211^{* *}$ & 107 \\
\hline \multicolumn{1}{c}{ Institutional Barriers vs. Age of Respondent } & \\
\hline Funding & $-0.205^{* *}$ & 107 \\
Inertia of the science system & -0.084 & 107 \\
\hline
\end{tabular}

Sig. (two-tails): **=P value $<0.05 ; * * *=\mathrm{P}$ value $<0.01$

The correlations show that operational barriers increase with the age of the respondent whilst institutional barriers, especially funding for open science activities, decrease with the age of the respondent.

Amongst the operational barriers, it is significant (p-value < 0.01 ) the correlation between 'assessing the quality and the impact of the research results' and age.

Concluding, thus far we have seen that open access to publication, dissemination activities and, importantly, access to open data are the key elements of open science both in terms of usage and of impact on the research activities. Other open science practices and research outcomes are also used widely by research professionals, although their impact on the advancement of science is not considered as determinant as other practices and outcomes. Moreover, researchers and research professionals reported that they found it useful to access the work of other researchers and research professionals, which has been made available openly but are often reluctant to share the outcomes of their own research openly for others to use. The uptake of open science practices or the diffusion of some research outcome openly varies also according to the field of science the research professionals are working in, the type of organisation they work at and their age/career status. Nonetheless, barriers to a wider diffusion of open science, both operational and institutional, affect the diffusion of open science. In particular the inertia of the research system to embrace open science practices is seen as a hindrance by the largest majority of the research professionals that have responded to our questionnaire.

\section{Discussion and conclusions}

This research presented highlights the great complexity of the science system and the relations amongst the components of such a system, especially during the current period of transformation in the process of the practice of science. A degree of this complexity is due to the relationships between research professionals and the research organisations within which they work. Several factors are at play, some are related to the attitudes and preferences of the research professionals and some are institutional.

From the literature review and the workshop we found that in many circumstances research professionals and their employers have aligned interests in open science, especially when it concerns the final outcome: publications. However, open science has demonstrated it has much more to offer to researcher professionals, from project conception to pooling of data archives, public engagement, alternative funding methods (crowd funding) and dissemination of research findings. The range of opportunities for outreaching and collaboration activities is virtually limited only by the imagination of the researchers. Yet these opportunities are often weighted against the benefits involved in following traditional practices. This usually means maintaining research progress as confidential until a claim to priority of discovery over the research findings can be made. Our analysis suggests this behaviour is customary in almost all organisations and is a consequence of the rewards system in place which is a contract between the research professional and her/his employer that does not reward full disclosure of the scientific process. 
The incentive system in place is shown to be firmly linked to the traditional process of knowledge creation and dissemination based on peer-reviewed publications in high-ranking journals. In the words of Nielsen: [this] is perhaps the most open system for the transmission of knowledge that could be built with seventeenth-century media (Nielsen, 2011, p 183). With such a precise definition of the objectives in place, the remit of the researcher is constrained between their organisation's 'visions' and 'mission statements' which encourage collaborations and openness $^{7}$ and the incentive to exert caution in disclosing research findings until these are certified by a certain type of publication. Perhaps for this reason, the respondents' opinions of the open science movement are much more timid that we expected albeit there are marginally greater expectations that open science can act as an 'opportunity leveller' between poorly resourced research organisations (public and private) and their more richly endowed counterparts. The cautious approach to open science is also supported by the views of the respondents that highquality peer-reviewed publications should be sought as a primary aim of the scientist and in order to achieve this goal, a certain degree of confidentiality at the initial phase of the research process is necessary. In particular, the avenue of publication - high-quality peer-reviewed journals - when seen together with the operational barriers, reinforces a narrative that privileges traditional publications as a guarantee of scientific legitimacy.

Nonetheless, open science practices are used by respondents and such use is matched by the impact that these might have in driving further the quest for new knowledge creation and dissemination. This aspect has been acknowledged by all respondents but the analysis of the correspondence between the use of some aspects of open science and the impact these have on research leads us to think that the interests of research professionals in some open science practices such as blogs, research social networks, reviews or crowd-sourced initiatives might be motivated by reasons other than impact. These might be in the realm of professional curiosity or sense of belonging to the science community.

We also investigated the usefulness of some of the common outcomes of the scientific process involving most of the steps of knowledge creation and dissemination and the propensity of the respondents to share these outcomes publicly (see tables 6 and 7 - Usefulness and Sharing). In this case we found that the outcomes leading directly to the process of publication and of dissemination of research findings mirrors the process in the traditional idea of science where publications, bibliographies, figures, presentations and support material are considered very useful and the willingness to share of the respondents is also correspondingly high. Conversely, research outcomes that might either affect the research professional's reputation, their claim to priority or that might jeopardise further exploitation of their research effort, are considered very useful but are shared less willingly. The first examples encompass drafts and incomplete publications and negative results whilst the last includes datasets, research logs and annotations and comments. We have highlighted some difference in the sharing behaviours present in the various disciplines: in the natural sciences, engineering and technology and the social sciences, respondents were keener to share than professionals in the medical and health sciences and agriculture ${ }^{8}$. Some differences in the propensity to share research outcomes are also significant between groups of respondents, for example, respondents older than 50 although considering publicly available research findings useful for their own research activities do share consistently less often than younger researchers. This factor can possibly be explained either by the constraints on the time available to share own resources or by the lack of the necessary skills to use newer networking tools ${ }^{9}$. Certainly, access to funding does not constitute an explanation for the poor sharing behaviour of senior academics and research professionals because from the analysis of barriers, we found that funding constraints decrease with seniority.

As mentioned earlier we also explored barriers to the uptake of open science. Operational barriers, the barriers hindering the practical application of open science initiatives have some effect on the uptake of open science but these are limited in terms of scope and extent. The most significant barrier concerns the assessment of the quality and the impact of research results when these are not published in the traditional form. The narrative emerging from the study of operation barriers is that the burden of 'assessing the quality and the impact of research output' is somehow outsourced (or surrendered) to traditional peer-review journals. The reason for this may either be that researchers have little time to dedicate to the verification of the scientific claims made in open science outcomes or that they are not familiar with the tools of open science. It is also noteworthy that this attitude toward open science increases with the age (and career progression) of researchers. In other words, older respondents, either because they lack the time to verify the claims presented in perceived lesser journals or the skills to trawl through open science outcomes, rely on high-quality journals (either open access or traditional subscription journals) for their rigorous process of peer review - either real or perceived - as a guarantee against misconduct and scientific fraud. 
Institutional barriers, those linked to the governing of the research process within universities and other research organisations play a determinant role in the uptake of open science. These types of barriers operate at the organisation-researcher level and are caused by the misalignment of interests between the parties affecting the system of incentives, especially when it comes to promotion and career advancement of academic and research professionals.

Our findings are in line with the emerging literature on open science and have indeed brought to the fore the point that scientific effort is organised in a system of interconnected stakeholders whose practices are definitely changing. Contextually, we can see that although the effort to adopt open science practices by researchers and by research organisations is driven more by enthusiasm than a strategic approach to opening up of the scientific process, the relationships between universities and other research organisations and their academic and research professional employees is still governed by the policies of traditional science. Research organisations are still extremely slow in integrating open science within their routines except for those open science practices which are 1) in line with the traditional science policies which are currently in force within the institution and 2) there is a funding line for their implementation.

\section{Limitations of the study and final remarks}

We wish to remind the reader that this study is exploratory, as the sample, though drawing from a community of research professionals with some knowledge of open science both as users and contributors, is limited in terms of number of respondents and concentrates uniquely on the relationships between use/impact, drivers and barriers to open science. Moreover, the sample is geographically skewed in favour of European respondents hence, although it does not emerge from the analysis, it may reproduce a Europe-centric view of open science with marginal inputs from other parts of the world.

Nonetheless, this exploration has demonstrated valuable insights into particular aspects of the relationships between research professionals and research organisations and has identified promising perceptions for a roadmap for further research.

With regard to this last observation, empirical and conceptual research on the theme of open science is therefore encouraged. Fruitful lines of research will necessarily involve a deeper understanding of the scientific process and its evolution by means of the introduction and diffusion of more web-rich technologies in carrying out research. This, as highlighted in the present study, alters the balance of interests between the parties. This paper took into consideration only the relationship between research professionals and research performing organisations uncovering that research professionals freely engage in open science practices even if the participation cost outweighs the return on their work in terms of career progression. The study has also shown that the usefulness of openly shared, scientific outcomes is considered positively yet, research professionals have little or no incentives to publicly share the results of their unpublished research.

The reasons for this behaviour can be explained by the operational barriers to open science. More importantly, such behaviour seems to be informed predominantly by institutional inertia and in particular by the organisations that are failing to recognise the contribution of research professionals to the creation and diffusion of knowledge, when this is provided in modes other than the research papers published in highly rated peer-reviewed journals.

Issues relating to funding of open science initiatives have also been found to be a determinant barrier to the uptake of open science. Consequently, as modes of public funding for scientific research are changing in order to accommodate new open science practices there is an identified need for further investigation of resourcing. This point is particularly important as open science has great potential in the advancement of knowledge and its wider and faster dissemination, whilst constraints on public budgets and debates on the orientation of the scientific effort towards societal challenges are at the centre of the policy makers' agendas.

\section{Acknowledgements:}

Financial support from the European Commission, Directorate General of Research and Innovation, contract 30-CE0496945/00-23 is gratefully acknowledged. The authors are grateful for the work undertaken by the Commission services, INNO group and SQW for the organisation of the workshop and the contributions of the participants. The 
opinions herein expressed are not necessarily those of the sponsor or the participants, the authors are solely responsible for the content of the paper and usual caveats apply.

\footnotetext{
${ }^{1}$ This essay does not enter into the debate on the terminology: Science 2.0, Open Science, eScience or New Science. In the study, we opted for Open Science as Science 2.0 is linked to the Information and Communication Technological Platform upon which the new scientific process is being increasingly undertaken, the Web 2.0. Yet, the Web 2.0 is increasingly morphing into 'the Internet of Things' whereby semantic technologies are systematically introduced and used in rich-web contents, consequently the next wave of Web 3.0 is seamlessly taking shape.

${ }^{2}$ Influential work on the nature of science, the scientific revolution and the instituted rules of science are: Ziman, (1968); Kuhn (1962); Cournand (1977) amongst others.

${ }^{3}$ The tension between openness and secrecy is rather more complex than we stated above (David, 2004 p.577 and 578). It sees juxtaposed the interests of the public in supporting open science for its objectives are the maximisation of the rate of growth of the stock of knowledge versus the private interests to secrecy, in view of the exclusive acquisition and the application of knowledge for the appropriation of the rent or personal gain. The resulting system of science, organised accordingly to the principles of open science is therefore the result of a long evolutionary process that entailed institutional change amidst the resolution of the agency problems between research performers and funding agencies rather than a "solution-by-design" implemented for the goodness of science.

${ }^{4}$ See http://doaj.org/ for the Directory of Open Access Journals (DOAJ).

${ }^{5}$ This, coupled with the observation that the price per subscription of scholarly publications rose at a rate much above the Consumer Price Index (CPI), constituted the precondition for the demise of the traditional scholarly publishing industry in the mind of many practitioners. Panitch and Michalak (2005) estimated that members of the Association of Research Libraries in 2004 were paying 215\% more per each subscription than they were paying in 1986 against a CPI increase of only 68\% during the same period. Considering also that the number of subscriptions also increased the greater outlay for research libraries had become highly onerous. Van Noorden (2013) provides an interesting update on revenues and costs of publications.

${ }^{6}$ The Journal of Young Pharmacists describes itself as the first open access source for research concerning negative results. Journal of Negative Results in BioMedicine is an open access, peer-reviewed, online journal that provides a platform for the publication and discussion of unexpected, controversial, provocative and/or negative results in the context of current tenets.

${ }^{7}$ Some responders have highlighted that there is a generalised enthusiasm within their organisation and amongst their peers even though there is little understanding of what opening the scientific process entails. The discussion held at the workshop informed that usually open science initiatives within the organisations are taken only in accordance with contractual terms: if the grant or funding contract allows or demands that publications are placed in open access repositories (either golden or green) and/or if the grant agreement involves also the curation and the publication of data. Moreover, open science practices are encouraged within the limit that they do not affect the organisation's interests. Other than this, open science is practised at the expenses/advantages of the research professionals in their personal capacity.

${ }^{8}$ The level of aggregation used in exploring this factor is the 1 digit of the Field of Science (FOS, 2007) classification. It is however legitimate to expect that significant variation might be present within sub-field of science. This level of granularity could not be investigated given the nature of our sample.

${ }^{9}$ Age can be seen as a proxy for career advancement, in this case it is consistent to think that career academics and research professional might have time constraints, moreover, the literature agrees that baby boomers - those born before 1964 - find relatively more cumbersome the use of Web 2.0 technologies compared to people of the "X-generation" - those born between 1965 and 1980 - the digital natives - those born after 1980.
} 


\section{References}

Andreoli-Versbach, P., \& Mueller-Langer, F. (2014). Open access to data: An ideal professed but not practised. Research Policy, 43(9) 16211633.

Antelman, K. (2004). Do open-access articles have a greater research impact? College \& research libraries, 65(5), 372-382.

Bartling, S., \& Friesike, S. (2014). Towards Another Scientific Revolution. In Opening Science (pp. 3-15). Springer International Publishing.

Berman, F., \& Cerf, V. (2013). Who Will Pay for Public Access to Research Data? Science, 341(6146), 616-617.

Björk, B.-C., \& Solomon, D. (2012). Open access versus subscription journals: a comparison of scientific impact. BMC Medicine 10(73)

Burgelman, J.-C., Osimo, D., \& Bogdanowicz, M. (2010). Science 2.0 (change will happen....). First Monday, 15(7).

Buschman, M., \& Michalek, A. (2013). Are alternative metrics still alternative? Bulletin of the American Society for Information Science and Technology, 39(4), 35-39.

Carayannis, EG, \& Campbell, DFJ In Carayannis EG, Campbell DFJ (Eds.) (2006). Knowledge creation, diffusion, and use in innovation networks and knowledge clusters. A comparative systems approach across the United States, Europe and Asia (pp. 1-25) Praeger, Westporti.

Choudhury, S., Fishman, J. R., McGowan, M. L., \& Juengst, E. T. (2014). Big data, open science and the brain: lessons learned from genomics. Frontiers in Human Neuroscience, 8.

Cournand, A. (1977). The code of the scientist and its relationship to ethics. Science, 198(4318), 699-705.

Dallmeier-Tiessen, S., Goerner, B., Darby, R., Hyppoelae, J., Igo-Kemenes, P., Kahn, D., Lambert, S., Lengenfelder, A., Leonard, C., Mele, S., Polydoratou, P., Ross, D., Ruiz-Perez, S., Schimmer, R., Swaisland, M., \& van der, Stelt, W. (2010). Open access publishing - models and attributes. Max Planck Digital Library/Informationsversorgung.

David, P. A. (2004). Understanding the emergence of 'open science' institutions: functionalist economics in historical context. Industrial and Corporate Change,13(4), 571-589.

David, P. A. (2005). From keeping 'nature's secrets' to the institutionalization of 'open science'. Code. Collaborative Ownership and the Digital Economy. The MIT Press, Cambridge.

Eamon, W. (1985). From the secrets of nature to public knowledge: The origins of the concept of openness in science. Minerva, 23(3), 321-347.

European Commission. (2012). Towards better access to scientific information: Boosting the benefits of public investments in research. Brussels.

Fanelli, D. (2012) Negative results are disappearing from most disciplines and countries. Scientometrics, 90, 891-904.

Fecher, B., \& Friesike, S. (2014). Open Science: One Term, Five Schools of Thought. In Opening Science (pp. 17-47). Springer International Publishing.

Field of Science (FOS) (2007). Revised Field Of Science And Technology (FOS) Classification in the Frascati Manual, available at http://www.oecd.org/science/inno/38235147.pdf (Accessed online 18/4/15)

Foster, W. S., \& Putos, S. M. (2014). Neglecting the null: the pitfalls of underreporting negative results in preclinical research. UOJM, 4(1), 3134

Franzoni, C., \& Sauermann, H. (2014). Crowd science: The organization of scientific research in open collaborative projects. Research Policy, 43(1), 1-20.

Gaulé, P., \& Maystre, N. (2011). Getting cited: Does open access help? Research Policy, 40(10), 1332-1338.

Gibbons, M., Limoges, C., Nowotny, H., Schwartzman, S., Scott, P., \& Trow, M. (1994). The new production of knowledge: The dynamics of science and research in contemporary societies. Sage Publications Ltd.: London.

Goetz, T. (2007). Freeing the dark data of failed scientific experiments. Wired Magazine, 15(10), 15-10.

Gorgolewski, K. J., Margulies, D. S., \& Milham, M. P. (2013). Making data sharing count: a publication-based solution. Frontiers in neuroscience, 7:9.

Grand, A., Wilkinson, C., Bultitude, K., \& Winfield A.F.T. (2014). Mapping the hinterland: Data issues in open science. Public Understanding of Science. 1-17. DOI: $10.1177 / 0963662514530374$

Haeussler, C., Jiang, L., Thursby, J., \& Thursby, M. (2014). Specific and general information sharing among competing academic researchers. Research Policy, 43(3), 465-475.

Harnad, S. (1994). Publicly retrievable FTP archives for esoteric science and scholarship: a subversive proposal. Scholarly Journals at the Crossroads: A Subversive Proposal for Electronic Publishing.

Harnad, S., \& Brody, T. (2004). Comparing the impact of open access (OA) vs. non-OA articles in the same journals. D-lib Magazine, 10(6).

Hayes, A., \& Hunter, J. (2012). Why is publication of negative clinical trial data important? British Journal of Pharmacology, $167(7), 1395-1397$.

Kuhn, T. S. (1962). The Structure of Scientific Revolutions. University of Chicago Press.

Kundoor, V., \& Mueen, A. K. (2010). Uncovering negative results: Introducing an open access journal "Journal of Pharmaceutical Negative Results". Journal of young pharmacists: JYP, 2(4), 339.

McVeigh, M. E. (2004). Open access journals in the ISI citation databases: analysis of impact factors and citation patterns: a citation study from Thomson Scientific.

Merton, R. K. (1942). The Normative Structure of Science. in Merton R. K. (1973) The Sociology of Science. Chicago: University of Chicago Press (p267-278).

Merton, R. K. (1973). The sociology of science: Theoretical and empirical investigations. University of Chicago press.

Nature (2011). A little knowledge. Nature 472: 135.

Nielsen, M. (2011). Reinventing Discovery: The New Era of Networked Science. New Jersey: Princeton University Press.

Nowotny, H., Scott, P., \& Gibbons, M. (2001). Re-thinking science: knowledge and the public in an age of uncertainty. Cambridge: Polity Press.

OECD. (2007). OECD Principles and Guidelines for Access to Research Data from Public Funding. Available from http://www.oecd.org/science/sci-tech/38500813.pdf.

Okerson, A., \& O'Donnell, J. J. (1995). Scholarly journals at the crossroads: a subversive proposal for electronic publishing: Association of Research Libraries.

Pampel, H., \& Dallmeier-Tiessen, S. (2014). Open Research Data: From Vision to Practice. In Opening Science (pp. 213-224). Springer International Publishing.

Panitch, J. M., \& Michalak, S. (2005). The serials crisis: a white paper for the UNC-Chapel Hill Scholarly Communications Convocation. Chapel Hill, NC: University of North Carolina. Retrieved, 3(17), 2006.

Peters, M.A. \& Roberts, P. (2011). The Virtues of Openness. Paradigm Publishers.

Peters, M.A. (2010). Openness, Web 2.0 Technology, and Open Science. Policy Futures in England, 8(5), 567-574 
Polanyi, M. (1962). The Republic of Science: its Political and Economic Theory. Minerva, I(1), 54-73. (Re-issue Minerva, 2000, 38(1), 1-21).

Popper, K. R. (1935). The logic of scientific discovery. (First English edition published 1959).

Priem, J., Taraborelli, D., Groth, P. and Neylon, C. (2010). Altmetrics: a Manifesto. Available at: http://altmetrics.org/manifesto/

Rinaldi, A. (2014). Spinning the web of open science. EMBO reports, 15(4), 342-346.

Sanderson (2008). Data on display - Two researchers explain why they're posting their experimental results online. Nature. doi:10.1038/455273a

Smart, R. G. (1964). The importance of negative results in psychological research. Canadian Psychologist/Psychologie Canadienne, 5(4), 225.

Solomon, D. J., Laakso, M., \& Björk B.-C. (2013). A longitudinal comparison of citation rates and growth among open access journals. Journal of Informetrics, 7(3), 642-650.

Van Noorden, R. (2013). The true cost of science publishing. Nature, 495(7442), 426-429.

Wagner, C. S. (2008). The new invisible college. Brookings Press, Washington, DC.

Waldrop, M. M. (2008). Science 2.0. Scientific American, 298(5), 68-73.

Wellcome Trust (2003). Sharing Data from Large-scale Biological Research Projects: A System of Tripartite Responsibility, Report of a meeting organized by the Wellcome Trust and held on 14-15 January 2003 at Fort Lauderdale, USA. The Wellcome Trust, 2003.

Whyte, A., \& Pryor, G. (2011). Open science in practice: Researcher perspectives and participation. International Journal of Digital Curation, 6(1), 199-213.

Wilcox, A. J. (2014) A positive approach to negative results. Epidemiology, 25(2), 165.

Wilhelm, E. E., Oster, E., \& Shoulson, I. (2014). Approaches and costs for sharing clinical research data. Journal of the American Medical Association, 311(12): 1201-1202.

Wilkins, J. S. (2008). The roles, reasons and restrictions of science blogs. Trends in ecology \& evolution, 23(8), 411-413.

Ziman, J. M. (1968). Public knowledge: An essay concerning the social dimension of science (Vol. 519): CUP Archive.

Dimitri Gagliardi, Deborah Cox, Yanchao Li

Manchester Institute of Innovation Research, Manchester Business School

The University of Manchester 